\section{International Scientific Journal Theoretical \& Applied Science}

\author{
p-ISSN: 2308-4944 (print) e-ISSN: 2409-0085 (online) \\ Year: $2016 \quad$ Issue: 1 Volume: 33 \\ Published: $30.01 .2016 \quad$ http://T-Science.org
}

Marfua Azizovna Khamidova

professor, doctor of art criticism, professor of the State Conservatory of Uzbekistan, academician of the Kazakh national academy of arts mirzokozimxon@gmail.com

SECTION 16. Music. Cinema art. Theatre.

\title{
OPERA OF THE 19th CENTURY IN THE ASPECT OF STYLISTIC TRANSFORMATIONS
}

Abstract: In this article European Opera of the 19th century is considered in terms of stylistic transformations, from the era of late classicism to romanticism and verismo. Here the characteristic of Opera creativity of various composers from the point of view of the implementation of the ideas of musical romanticism and verismo, examines the state of the vocal art.

Key words: Bel Canto, cantilena Largo, figurative singing, improvisation, classicism, romanticism music, ornamental and variational techniques, contrasting imagery, the lyricism, vocals, full band, opera form, the verismo.

Language: Russian

Citation: Khamidova MA (2016) OPERA OF THE 19th CENTURY IN THE ASPECT OF STYLISTIC TRANSFORMATIONS. ISJ Theoretical \& Applied Science, 01 (33): 149-153.

Soi: http://s-o-i.org/1.1/TAS-01-33-26 Doi: crossef http://dx.doi.org/10.15863/TAS.2016.01.33.26

\section{ОПЕРА ХІХ ВЕКА В АСПЕКТЕ СТИЛЕВЫХ ТРАНСФОРМАЦИЙ}

Аннотация: В настоящей статье европейская опера ХІХ века рассматривается в аспекте стилевых трансформаций, начиная от эпохи позднего классицизма до романтизма и веризма. Здесь дается характеристика оперного творчества ряда композиторов с точки зрения претворения идей музыкального романтизма и веризма, анализируется состояние вокального искусства.

Ключевые слова: bel canto, кантиленное largo, фигуративное пение, импровизация, классицизм, музыкальный романтизм, орнаментально-вариаџионные приемы, контрастная образность, лиризм, вокальные партии, полнозвучный диапазон, оперная форма, веризм.

Величайшее завоевание итальянской вокальной школы XVII - XIX вв. - bel canto, преодолев к концу XVIII - началу XIX века свои территориальные границы, становится достоянием других национальных культур (Франции, Германии, Испании, России). Тому способствовали, с одной стороны, гастроли знаменитых итальянских певцов, местные постановки с их участием, общеевропейская известность прославленных маэстро, с другой домашнее светское музицирование и вокальное обучение молодых людей силами приглашенных педагогов.

К тому времени внутри bel canto, где тоже шли процессы адаптации к новому репертуару, вначале только различались, а затем стали противопоставляться два направления: кантиленное largo с незначительными украшениями, а также фигуративное пение, отмеченное виртуозными орнаментальновариационными приемами и импровизациями, демонстрирующими высокий класс профессионально-технического мастерства. Характерное особенно для кастратов, участие которых в спектаклях ещё более подчеркивало условность оперного жанра, второе направление, усиливая декоративность постановок и вызывая далёкие от жизни ассоциации, служило мифологизированной идее, изображая, но, не выражая внутренний мир персонажей. И, если классицизм, при всей своей рациональности, художественной логике, соразмерности, разумности средств, не противился искусству такого рода, пытаясь обогатить его содержание героическим материалом, то романтизм отнесся к своему предшественнику вполне критически.

Авторов романтических опер интересовали не всемогущие боги, не сверхъестественные 
силы, а сложный мир чувств, страстей, переживаний одинокой личности, устремленной к несбыточной мечте, блуждающей по свету или гибнущей в тщетных поисках счастья и душевного покоя [21. 62].

Опера Людвига Вана Бетховена «Фиделио» (1805, либретто И. Зоннлейтнера и Г. Трейчке) как бы обобщает на высочайшем художественном уровне классицистские тенденции и открывает первые страницы музыкального романтизма. Исполненная действенности, напряженного драматизма, она соединила в себе не только ораториальные элементы, но и бытовые, комедийные сцены с развернутыми ариями, ансамблями, речитативами, оркестровыми страницами и разговорными диалогами, близкими к зингшпилю.

Вокальные партии многогранно отражали душевное состояние действующих лиц. Страстные и ликующие, светлые и грустные, они говорили об усложнении выразительных сфер и наступлении на оперную сцену новых героев любящих, сомневающихся, страждущих, борющихся за свои идеалы и ценности, главное несущих земные черты и человеческую глубину.

Объединяющим началом романтического стиля в музыке стал интерес к произведениям литературы и изобразительного искусства, к рыцарскому средневековью, экзотическим странам, к народным песенно-танцевальным истокам.

Контрастная образность, проникновенный лиризм, мелодическое богатство, а также возвышенная грусть и авторское сопереживание определяли поэтику камерно-симфонических, вокально-инструментальных произведений Вебера, Шуберта, Мендельсона, Листа, Берлиоза, Шумана, Шопена, Мейербера, Вагнера - ярких представителей музыкального романтизма XIX века.

Романтическими мотивами любви к истории, средневековым героям и легендам пронизаны оперы «Вольный стрелок» - 1821 (либретто Ф.Кинда, по народным преданиям), «Эврианта» - 1823 (либретто Г. фон. Хези, по французской новелле XIII в.) Вебера.

Сюда же относятся «Пуритане» - 1835 (либретто К.Пеполи, по роману В.Скотта) Беллини; «Лючия ди Ламмермур» - 1835 (либретто С.Каммарано, по роману В.Скотта) Доницетти; «Вильгельм Телль» - 1829 (либретто В.Этьена и И.Би, по драме А.Лемьера) Россини.

В числе оперных сочинений, в которых с наибольшей очевидностью проявляется сочувствие героям в их романтических начинаниях: «Гугеноты» - 1836 (либретто Э.Скриба и Э.Дешана, по мотивам повести П.Мериме), «Пророк» - 1849 (либретто Э.Скриба) и «Роберт-дьявол» - 1831 (либретто Э.Скриба и Ж.Делавиня) Мейербера; «Тангейзер» - 1845 (либретто Вагнера, по саге XIII века), «Кольцо нибелунга» - 1876 (либретто Вагнера, по скандинавскому эпосу XIII века) и «Тристан и Изольда» - 1865 (либретто Вагнера, на основе романа Г.Страсбургского) Вагнера [4], [5], [6. 58], [11. 146].

«Лакме» Делиба уже адресует к излюбленным романтиками экзотическим сюжетам.

Свидетельством того, что композиторыромантики нередко искали вдохновение в произведениях литературной классики, является опера «Ромео и Джульетта» - 1867 (либретто Ж.Барбье и М.Карре, по трагедии Шекспира) Гуно, а также целый ряд других оперных сочинений («Отелло» Верди, по трагедии Шекспира, «Вильгельм Телль» Россини, по Шиллеру).

Литературным первоисточником служили также романы Виктора Гюго («Эрнани», «Король забавляется»), Вальтера Скотта («Ламмермурская невеста», «Пуритане» и «Елизавета, королева Английская»).

Разнообразные по темам и музыкальным средствам романтические оперы, раскрывая тонкий, ранимый и в то же время трепетный, щедрый на откровение и сострадание мир человеческой души, знаменовали собой новый этап оперно-исполнительского искусства, связанный с драматическими интонациями, экспрессией, правдиво передающими богатую гамму человеческих чувств и эмоций.

К этому времени на арене борьбы за вокальные приоритеты одерживают победу природные голоса - тенора и женские сопрано, соединившие техническое мастерство с кантиленой, выражая и правду, и мысль, и настроение.

Джоаккино Россини (1792-1868) выдающийся итальянский композитор, в своих операх «Итальянка в Алжире» - 1813 (либретто А.Анелли), «Золушка» - 1817 (либретто Я.Ферретти, по сказке Перро), «Севильский цирюльник» - 1816 (либретто Ч.Стербини), а также «Танкред», «Отелло», «Моисей», «Вильгельм Телль» раздвигает рамки оперы буффа и оперы - сериа социально-сатирическими и героическими мотивами. Великолепный знаток bel canto, сторонник льющихся звуков, легкой эмиссии, сочетания певучести с блеском виртуозных каденций, рулад, он фиксирует в нотах колоратурные украшения, «посягнув» на свободу виртуозов-импровизаторов, подчинив пение драматургическим задачам [20], [21. 65].

Если комедиям Россини присущи меткость, реалистичность зарисовок, стремительность действия, сверкающее остроумие, театральность, 
живость ритмики и щедрость мелодики, бравурность пассажей и ясность оркестрового письма, то его серьёзные оперы отмечены героико-романтическими интонациями, монументальностью идейно-художественного замысла, достигаемыми посредством развернутых арий, величественных хоров и ярких оркестровых страниц.

Оперы Винченцо Беллини (1801-1835), такие как «Сомнамбула» (1831, либретто Ф.Романи), «Норма» (1831, либретто Ф.Романи, по трагедии А.Суме и Бельмонте), «Пуритане» (1835, либретто К.Пеполи, по роману В.Скотта), проникнутые лирико-патетическими мотивами, изящные по мелодике, мягкие по звучанию, утонченно-мечтательные по поэтике, а также блистательные, тщательно выверенные по форме, представляют собой наглядные образцы искусства bel canto.

В них нашел претворение и оперный речитатив, усовершенствованный, исполненный певучести и декламационной выразительности, что требовало высокого вокально-технического мастерства, исполнительского дарования, способного раскрыть сложную и многокрасочную палитру эмоциональных переживаний оперных персонажей [21.65].

В различных жанрах (буффа, французская комическая опера, большая французская опера, мелодрама) работает Гаэтано Доницетти (17971848) - автор известных опер «Любовный напиток» (1832, либретто Ф.Романи по пьесе Э. Скриба) [12], «Лукреция Борджиа» (1833, либретто Ф.Романи по драме В.Гюго), «Лючия ди Ламмермур» (1835, либретто С.Каммарано по роману В.Скотта), «Дон Паскуале» (1843, либретто Дж. Руффини) и т.д. Примечательные богатством оркестрового и гармонического письма, ансамблевой целостностью и контрастной образностью, сочные и колоритные по музыкальным характеристикам, они отличаются также преломлением в неразрывном единстве школы cantabile и figurato.

Россини, Беллини, Доницетти представляли Неаполитанскую школу, продолжая и последовательно развивая, согласно с художественно-эстетическими установками своей эпохи, лучшие её традиции, связанные с раскрытием внутреннего мира человека. Лучшие певцы эпохи Джультруда Ригетти-Джорджи, Андреа Нодзари, Изабелла Анджела Кольбран, Луиджи Дзамбони, Джудитта Паста, Джованни Баттиста Рубини, Джулия Гризи, Антонио Тамбурини, Луиджи Лаблаш подчинили этой задаче весь арсенал вокально-технических средств.

Идеи музыкального романтизма утверждение человеческого достоинства, обличение социальной морали, национально- освободительные мотивы - в полную силу заявили о себе в творчестве великого итальянского композитора Джузеппе Верди (1813-1901). В операх «Набукко», Атилла», «Жанна д’ Арк» получила воплощение столь актуальная для романтиков национальная идея.

В основе «Риголетто» - 1851 (либретто Ф.М.Пиаве, по драме В.Гюго), «Травиата» - 1863 (либретто Ф.М.Пиаве, по драме А.Дюма-сына) судьбы, чаяния, надежды простых людей, которые пытаются противостоять жестокой реальности и сохранить своё человеческое достоинство.

В таких операх как «Трубадур» (1853, либретто С.Каммарано, по драме Г.Гутьерреса); «Бал-маскарад» (1859, либретто А.Соммы); «Дон Карлос» (1867, либретто Ж.Мери и К. дю Локля, по драме Шиллера); «Аида» (1871, либретто А.Гисланцони); «Отелло» (1887, либретто А.Бойто, по трагедии Шекспира); «Фальстаф» (1893, либретто А.Бойто, по комедии Шекспира) Верди главное внимание обращает на развитие драматического конфликта, эмоциональнопсихологическую достоверность музыкальных образов. Его неизменно привлекают душевное самочувствие личности, преисполненной романтических надежд и чаяний, бросившей вызов обществу, где процветает ложь и лицемерие [7], [8], [9], [10].

Верди ищет для своих сочинений новые темы и вокально-технические средства, нередко используя высокую тесситуру мужского голоса. Действенность, яркая театральность, острота противопоставлений, а также драматически насыщенные ансамбли и сольные партии его героев требовали органики вокального и актерского мастерства, широкого, полнозвучного диапазона и прикрытия верхних его участков, ровности, однородности звучания, а также усиленной работы смешанного регистра. Колоратурные украшения как важнейшие атрибуты певческой культуры играют не декоративную роль, а служат обрисовке персонажей, выявлению тех или иных красок, обусловленных художественнодраматургическими задачами.

Непревзойденный мастер оперной формы и искусства bel canto Верди стремится к жанровостилистическому единству разнообразных частей композиции. Отсюда и избирательность приемов в вокальных партиях, которые строились с учетом природы всех типов голосов, а также специфики певческого механизма, что стало ещё одной причиной широкой «репертуарности» произведений композитора во всём мире.

На операх Верди вырос знаменитый «вердиевский баритон» - исполнитель героических партий Дж.Ронкони. Пройдя его оперную и вокальную школу, достигли мировой

ISPC Perspectives in science for $\mathbf{2 0 1 6}$, 
известности Марианна Барбьери - Нини, Варези Феличе, Франческо Таманьо, Фраскини Гаэтано, Де Джули Тереза, София Крувелли, Виктор Морель, Леоне Джиральдони и др.

Романтические черты (экзотический сюжет, восточный колорит, контрастная образность) присущи и операм Жоржа Бизе «Искатели жемчуга» (1863), «Пертская красавица» (1866), «Джамиле» (1871), которые отмечены пластически выразительной и узорчатой методикой, сочностью, красочностью массовых сцен. Близостью к речевым краскам отличаются камерные лирические оперы «Манон» (1884), «Вертер» (1886) Жюля Масне, внесшего ощутимый вклад в развитие ариозноречитативного вокального стиля.

Тяготея к разработке женских образов поэтичных, переменчивых в настроении, жертвенных, композитор стремится к сгущенному психологизму образов, к созданию колоритных человеческих типов. Вокальные партии приобретали то яркие мелодические очертания с певучими и пылкими фразами, то острую и гибкую речитативность, то мягкую, задумчивую песенность, подчеркивая многоплановость и сложность жизненных ситуаций, которые переживают герои.

В конце XIX века в искусстве возникает новое направление - веризм (от слова vero правдивый, истинный), характерные черты которого отображение жизни социальных низов, мелодраматическое наполнение любовной драмы на фоне простой бытовой коллизии. Веристская опера, демократичная по идейно-содержательной сущности, примечательна открытостью, душевной простотой героев, выражаемых яркой мелодией. Развивая кантабиле широкого дыхания, она не поддавалась соблазну украшательства, что служило усилению в ней реалистических черт.

Оперы «Паяцы» Руджеро Леонкавалло (1892, либретто автора) [13], «Сельская честь» Пьетро Масканьи (1890, либретто Дж.ТарджониТоццетти и Г. Менаши, по пьесе Дж.Верги) [15], несмотря на банальность сюжетного развития, отмечены стремлением к правде эмоционального высказывания. Переживаемые героями неистовые страсти, предельная напряженность душевных сил, скорбь, отчаяние, которые сменяются взволнованной лирикой, патетикой или же элегичностью, созерцательностью, отрешенностью, определяют стилистику певческого искусства, основанного на свободно льющейся и эмоционально насыщенной кантилене с весьма сдержанным применением колоратуры.

Выдающийся итальянский композитор Джакомо Пуччини (1858-1924) раздвигает рамки веризма волнующей современной тематикой, живыми, колоритными характерами, проявляя творческую и психологическую проницательность, знание не только сцены, но и реальной действительности. Его операм «Манон Леско» (1983, либретто Л.Иллики, Д.Оливы, М.Праги, Дж. Рикорди, по роману А.Прево), «Богема» (1896, либретто Дж. Джакозы и Л. Иллики, по роману А.Мюрже), «Тоска» (1900, либретто Дж.Джакозы и Л.Иллики, по драме В.Сарду), «Чио-Чио-Сан» (1904, либретто Дж.Джакозы и Л.Иллики, по драме Д.Беласко) присущи стремительное развитие действия, острые драматические положения, страстный порыв, взволнованность [16], [17],[18].

Мастер вокального письма Пуччини органически соединил певучие арии и мелодичный речитатив. Напевные, задушевные, пылкие, тревожные, исполненные драматической экспрессии, а порой живописных, акварельных красок, они передают одухотвореннопоэтический мир героев, открытый для сострадания и понимания.

Оперное творчество конца XIX - начала XX века протекало под влиянием различных направлений: неоклассицистских, импрессионистских, экспрессионистских, символистских, натуралистических, реалистических. Детищами своего времени стали и оперы Рихарда Штрауса «Саломея» (1905), «Электра» (1908), «Кавалер роз» (1910), где проступали приоритеты и настроения эпохи. Усилив в декламационно-речевой партитуре диссонирующие и контрастирующие элементы, рельефность мелодического рисунка, композитор сохранил цельность и прозрачность оркестровой фактуры, призывая в вокально-исполнительском плане к экспрессивному высказыванию, преувеличенной эмоции, сочетающейся порой с камерно-исповедальным звучанием голоса.

На этой высокой и гуманной ноте, обращенной к сердцам людей и призывающей к любви к человеку, завершается целая эпоха в истории оперы. Эпохи, давшей великолепные образцы оперно-исполнительского искусства, стимулировавшей развитие национальных школ, служившей благодатной почвой для творческого поиска и связующим звеном между классицистской, романтической, веристской и реалистической оперой в разнообразных жанрово-стилевых проявлениях, которые обуславливали и вокально-технические средства выражения.

Своими достижениями на протяжении всего XIX века оперное творчество было обязано не только композиторам, но и певцам, и вокальным педагогам - практикам и теоретикам, ищущим образец идеального звукообраза, пути и методы его достижения, изучающим, анализирующим 


\begin{tabular}{l|lrl|l|ll} 
& ISRA (India) & $=\mathbf{1 . 3 4 4}$ & SIS (USA) & $=\mathbf{0 . 9 1 2}$ & ICV (Poland) & $=\mathbf{6 . 6 3 0}$ \\
Impact Factor: & ISI (Dubai, UAE) $=\mathbf{0 . 8 2 9}$ & PUHL (Russia) $=\mathbf{0 . 1 7 9}$ & PIF (India) & $=\mathbf{1 . 9 4 0}$ \\
& GIF (Australia) & $\mathbf{0 . 5 6 4}$ & ESJI (KZ) & $=\mathbf{1 . 0 4 2}$ & & \\
& JIF & $\mathbf{1 . 5 0 0}$ & SJIF (Morocco) $=\mathbf{2 . 0 3 1}$ & &
\end{tabular}

технологию сольного пения и его выразительный инструментарий

\section{References:}

1. Arnold Y (1898) Teoriya postanovki golosa po metodike staroy italyanskoy shkolii i primeneniye teorii $\mathrm{k}$ prakticheskomu obucheniyu obrazovaniyu pevcheskikh zvukov. SanktPeterburg.

2. Bagadurov VA (1956) Ocherki po istorii vokalnoy pedagogiki. 2 izd. pererab. i dop. Moskva, Muzgiz.

3. Vagner R (1911-1912) Moya djizn: Memuarii. Pisma. Dnevniki. - V 4 tt. Sankt-Peterburg.

4. Vagner R (1976) Klavir operii «Tangeyzer» (libretto Vagnera, po sage XIII veka). Moskva, Muziika.

5. Vagner R (1977) Klavir operii «Kolso nibelunga» (libretto Vagnera, po skandinavskomu eposu XIII veka). Moskva, Muziika.

6. Vagner R (1978) Klavir operii «Tristan i Izolda» (libretto Vagnera, na osnove romana G.Strasburgskogo). Moskva, Muziika.

7. Verdi D (1983) Klavir operii «Trubadur» (libretto S.Kammarano, po drame G.Guterresa). Moskva, Muziika.

8. Verdi D (1984) Klavir operii «Bal-maskarad» (libretto A.Sommii). Moskva, Muziika.

9. Verdi D (1985) Klavir operii «Don Karlos» (libretto J.Meri i K. dyu Loklya, po drame Shillera). Moskva, Muziika.

10. Verdi D (1985) Klavir operii «Otello» (libretto A.Boyto, po tragedii Shekspira). Moskva, Muziika.
11. Glikman I (1989) Meyerxold i muziikalniiy teatr. L.: SK.

12. Donitsetti G (1981) Klavir operii «Lyubovniiy napitok» (libretto F.Romani, po p'ese E. Skriba). Moskva, Muziika.

13. Leonkavallo R (1964) Klavir operii «Payatsii» (libretto kompozitora). Moskva, Muziika.

14. Lvov ML (1964) Iz istorii vokalnogo iskusstva. Moskva, Muziika.

15. Maskani P (1966) Klavir operii «Sel'skaya chest» (libretto Dj.Tardjoni-Totssetti i G. Menashi. po p'ese Dj.Vergi). Moskva, Muziika.

16. Puchchini D (1963) Klavir operii «Bogema» (libretto Dj. Djakozii i L. Illiki, po romanu A.Myurje). L.: Muzgiz.

17. Puchchini D (1962) Klavir operii «Toska» (libretto Dj.Djakozii i L.Illiki, po drame V.Sardu). L.: Muzgiz.

18. Puchchini D (1971) Klavir operii «Chio-ChioSan» (libretto Dj.Djakozii i L.Illiki, po drame D.Belasko). M.-L.: Muziika.

19. Roben SD (1925) Tekhnika peniya i yediniiy metod postanovki golosa. L.: Gosizdat.

20. Rossini D (1956) Klavir operii «Sevilskiy siryulnik» (libretto Ch.Sterbini). Moskva, Muzgiz.

21. Khamidova MA (2009) Bel canto v kontekste vokalno-ispolnitelskoy kulturii XIX veka /Xonandalik san'ati. Toshkent, San'at. 